\title{
Defining parameters for numerical modelling of fires
}

\author{
Zoltan Vass ${ }^{1}$, Adrian Bogdan Șimon-Marinică ${ }^{1}$, and Sorina Stănilă ${ }^{2}$ \\ ${ }^{1}$ National Institute for Research and Development in Mine Safety and Protection to Explosion - \\ INSEMEX, 32-34 G-ral Vasile Milea street, 332047, Petroșani, Hunedoara county, Romania \\ ${ }^{2}$ University of Petroşani, Faculty of Mechanical and Electrical Engineering, 20 Universităţii street, \\ 332006, Petroșani, Hunedoara county, Romania
}

\begin{abstract}
Fires caused by human activities are one of the main causes of losses in terms of both human lives and material and economic capital. To prevent these losses, it is necessary to perform the needed activities of research in the area of industrial fires, as such one of the methods of achieving this, is to perform computer aided numerical simulations of fires. By this process of computational modelling, we can determine the causes of the fires, and the mechanism by which the fire has propagated and developed. Also, numerical modelling of fires, can help in the development of procedures, and norms, which we can implement, to protect the personnel and to prevent material and economic losses.
\end{abstract}

\section{Introduction}

To better understand the evolution of fires, it is necessary to perform the necessary scientific research in this area. One of the possibilities of research on this issue, is the numerical simulation of the fires, using specific computational tools, available for this purpose. These computational tools can be of two type: software and hardware.

The hardware part of this is represented in the form of computing devices available, and the software component that is installed on the computing hardware, and these two components are used to perform the computational modelling of fires, and the visualization of the results.

In this paper, we will focus our attention on the Fire Dynamics Simulator version 6.7.1 of the software package.

\section{Parameters}

In order to successfully perform a numerical modelling of a fire, it is necessary to set up the necessary parameters for the simulation. These parameters are as follows: the computational domain, the mesh, the materials, the chemical reactions, the geometry, and data visualization.

\footnotetext{
* Corresponding author: vass.zoltan@insemex.ro
} 


\subsection{Computational domain}

The computational domain is a finite volume of space, inside which the process of numerical modelling is taking place. The parameters of the computational domain include the width, length and height of the domain, domain boundary type.

The width, length and height of the domain enclose a 3-dimensional volume of space, inside which the numerical computation is performed.

The domain boundary can be a closed type, or open type as illustrated by Fig. 1. In case of the former, the boundary is considered a solid wall, and no exchange of information is taking place between the inside and outside of the computational domain. In the case of the latter, the boundary is considered open and information can be exchanged between the interior and exterior of the domain. In the figure below is represented visually the computational domain in the two possible states. On the left is the domain with closed boundary, and on the right the domain with open boundary [1].
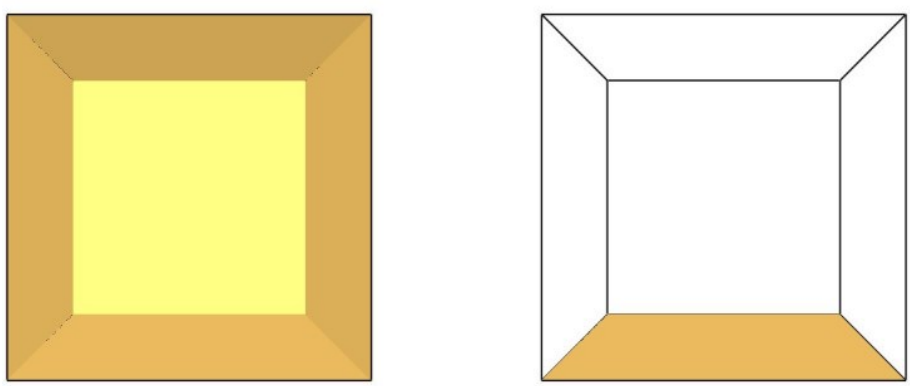

Fig. 1. Computational domain

\subsection{The mesh}

The mesh represents the breaking up of the computational domain into multiple small components called cells. The mesh is an important parameter of the numerical simulation due to the fact that it can determine the accuracy of the simulation.

If the mesh is composed of a large number of cells, the results of the numerical simulation will be very close to reality, however we have to keep in mind that in this case the time necessary to perform the numerical simulation will be very high.

In order to reduce the time necessary to complete the simulation, the mesh can be split into multiple sub-mesh components as illustrated in Fig. 2., each with different number of cells, and run the simulation in a parallel manner.
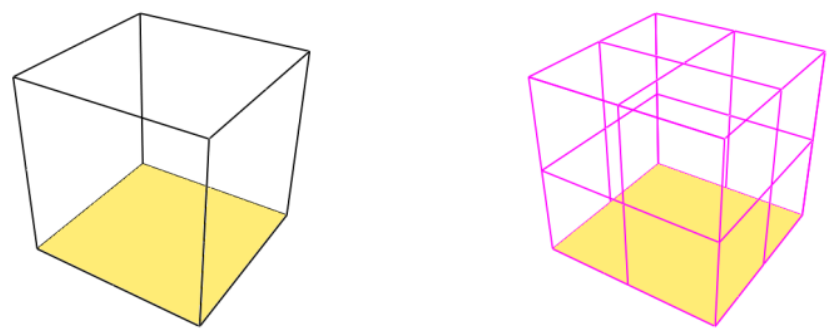

Fig. 2. Single and multiple mesh 
The quality of the mesh is a very important parameter for the simulation process. If it is set up incorrectly, the accuracy of the numerical simulation will be poor. It is recommended that the shape of the mesh cells to be of hexahedral type, that is the width, length and height of the cell to be equal to each other.

In case of multiple mesh simulations, each sub-mesh can have it' $\mathrm{s}$ own mesh resolution, that is the size of the cells are different from sub-mesh to sub-mesh. This is useful to reduce the necessary computational time, by using a sub-mesh with a larger cell size in areas of less importance, and using a sub-mesh with a small cell size in areas of the computational domain with a higher importance to our research.

In ideal conditions each sub-mesh should have the same resolution, however, when this is impractical, it is recommended that when a sub-mesh with a lower mesh resolution is placed next to a sub-mesh with a higher mesh resolution, the number of cells of the higher resolution sub-mesh to be an integral number of times of the cells of the sub-mesh with the lower resolution.

\subsection{Boundary Conditions}

All solid surfaces or obstacles present in the limits of the computational domain, have associated thermal boundary conditions, and other information specific to the combustion of the material of which the obstacles are made of.

The exchange of heat and materials from the solid surface is usually computed using empirical correlations, however, it is possible to compute the ongoing heat and material transfer using a Direct Numerical Simulation method.

\subsection{Geometry}

When performing a numerical simulation of a fire, it is necessary to define the geometry of the simulation.

The geometry consists of the totality of the elements inside of the computational domain such as walls, doors and other obstacles. Implicitly, the obstacles are considered inert components, in the sense that they not participate in the combustion process, however, they have a significant influence on the evolution of the fire, by controlling the flow of air and other elements inside the computational domain.

As mentioned above, the obstacles are considered inert initially, however by applying a material to these obstacles, they become components, that participate in the combustion process in an active manner.

\subsection{Materials}

Materials are a parameter of the numerical simulation of fires without which we cannot have a successful simulation of a fire. The simulation software must take into consideration the properties of materials associated to the different obstacles of the geometry, in order to compute the products of the combustion process.

To have a combustion process there have to be present three components essential to the combustion process. These components are oxygen, flammable materials and one or more ignition sources, as illustrated in Fig. 3.

When all the necessary components are present, the combustion process can take place. This process can evolve through four phases:

The incipient phase, of the fire, begins when heat, oxygen and a fuel source combine and have a chemical reaction resulting in a fire. This phase is also known as "ignition" phase and is usually represented by a very small fire which is characterized by a low energy 
output. When the combustion process is in the incipient phase, there is a possibility that the fire will extinguish on its own, before the following stages are reached.

The growth phase, begins when the materials and oxygen present, are used as fuel for the combustion. There are numerous factors affecting the growth stage including where the fire started, what combustibles are near it, ceiling height and the potential for "thermal layering". It is during this shortest of the 4 stages when a deadly "flashover" can occur; potentially trapping, injuring or killing firefighters.

Fully developed phase, when the growth stage has reached its maximum potential and all combustible materials have been ignited, a fire is considered fully developed. This is the hottest phase of a fire and the most dangerous for anybody trapped within.

Fig. 3. The triangle of combustion

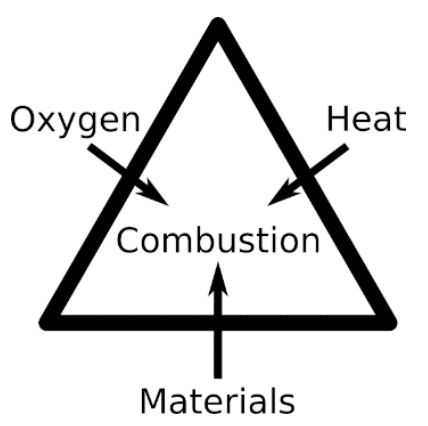

The decay phase, usually the longest stage of a fire, the decay stage is characterized by a significant decrease in oxygen or fuel, putting an end to the fire. Two common dangers during this stage are the existence of non-flaming combustibles, which can potentially start a new fire if not fully extinguished, and there is the danger of a backdraft when oxygen is reintroduced to a volatile, confined space.

\subsection{Combustion}

The software, solves numerically a form of the Navier-Stokes equations appropriate for low-speed, thermally-driven flow with an emphasis on smoke and heat transport from fires. The core algorithm is an explicit predictor-corrector scheme, second order accurate in space and time.

Turbulence is treated by means of Large Eddy Simulation. It is possible to perform a Direct Numerical Simulation, if the underlying numerical mesh is fine enough.

For most cases, the software uses a single step, mixing-controlled chemical reaction which uses three lumped species (a species representing a group of species). These lumped species are air, fuel, and products. By default, the last two lumped species are explicitly computed. Options are available to include multiple reactions and reactions that are not necessarily mixing-controlled.

\subsection{Data visualization}

After or during the process of simulation it is necessary to visualize the computed data. This data is recorded by the simulation software, and stored in computer memory for to be used at a later date.

The results of the simulation can be recorded at a specific point inside of the computational domain. The values recorded can be specific to the combustion process, such as the temperature, pressure, velocity, concentration of different chemical species 
participating in the process of combustion. Another way a data can be visualized is by recording of animated slices.

These animated slices represent a two-dimensional cross section of the computational domain, on which different values, presented previously, can be visually plotted. The animated slices are saved at each time step of the simulation process, thus giving us the possibility of creating animations of the simulation. In the Fig. 4., is presented one slice animation file at a specific point in time of the simulation process.
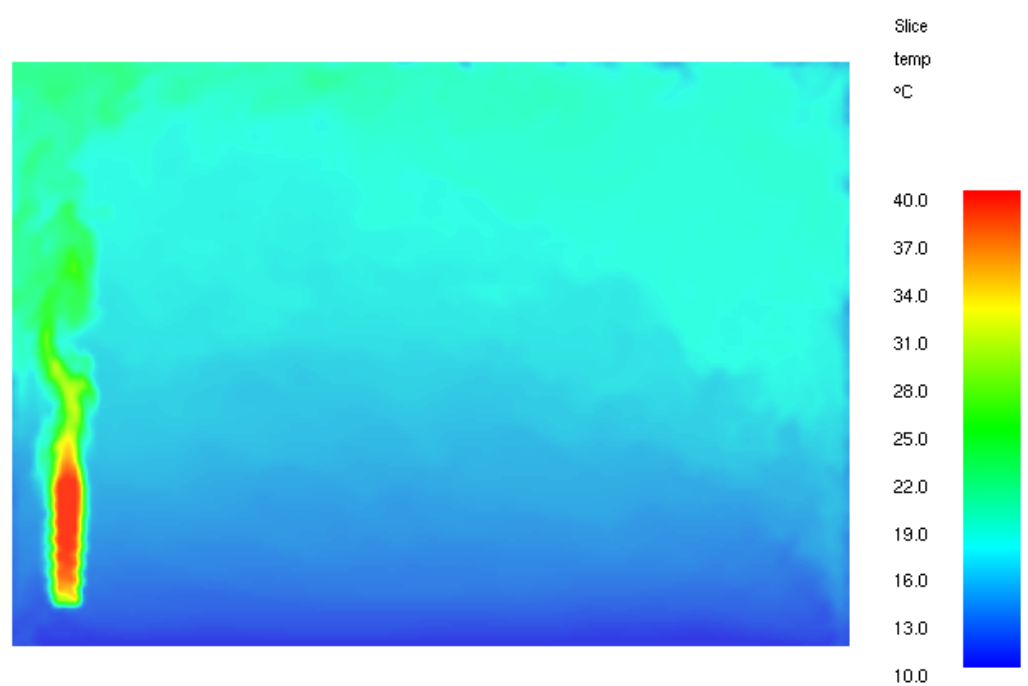

Time: 1000.0

Fig. 4. Representation of a slice file animation

\subsection{Time}

There is two type of time in the simulation process. One is the time maintained by the simulation software, and the other is the effective time consumed to complete the simulation.

This second time parameter is also known as "real time", and can be of variable length from a few hours to a few days.

\subsection{Ignition sources}

The ignition source initiates the burning process within a timeframe which represents the solids pyrolysis time and the gaseous phase induction time.

Once with the increase of the velocity increases the heat flow over surface and the time required for heat-up and for the solid's pyrolysis decreases. On the other hand, increases of gas velocity will results into a decrease of the flow's residence time. This phenomenon will delay the debut of the chemical reaction or even will avoid its' ignition.

The presence of a driven ignition (pilot) affects the burning process by local reduction of the induction time. The heat-up of the solid is the dominant mechanisms in the burning process, with a low gas flow velocity and a normal oxygen concentration. 
In the case of a non-driven ignition the induction time increases significantly, and flames occur spontaneously, as result of the step-by-step heating of the flammable material $[2]$.

\subsection{Heat release rate}

The Heat Release Rate (HRR) is not a basic property of a fuel and therefore it cannot be calculated from the physical properties of the material, being usually determined through tests.

In the Table 1 . below is highlighted the released heat quantity, measured for various situations [3]:

Table 1. Heat release rate for some materials and objects

\begin{tabular}{|l|l|}
\hline Heat Source & $\begin{array}{l}\text { Heat release rate } \\
\text { (HRR) }\end{array}$ \\
\hline A burning cigarette & $5 \mathrm{~W}$ \\
\hline A typical light bulb & $60 \mathrm{~W}$ \\
\hline A burning wastepaper basket & $100 \mathrm{~kW}$ \\
\hline A burning $1 \mathrm{~m}^{2}$ pool of gasoline & $2.5 \mathrm{MW}$ \\
\hline Burning wood pallets, stacked to a height of $3 \mathrm{~m}$ & $7 \mathrm{MW}$ \\
\hline Burning polystyrene jars, in $2 \mathrm{~m}^{2}$ cartons $4.9 \mathrm{~m}$ high & $30-40 \mathrm{MW}$ \\
\hline
\end{tabular}

\section{Conclusions}

Virtual computer modelling of events such as fires with an increased hazard level, provide possibilities for estimating the risks related to occupational health and safety, to the environment, buildings, material losses etc.

Taking into account the technological progress from the past years concerning the calculation power, there can be concluded that the virtual simulation of complex pyrogenic processes may be performed very well and the results obtained are close to the reality.

This paper was developed within the Nucleu-Programme, carried out with the support of Romanian Ministry of Research and Innovation, project no. PN-19-21-01-05, project title: Fundamental research and computer simulations on the initiation of explosive gas mixtures by potential sources of ignition of a different nature (in Romanian: Cercetări fundamentale și simulări computerizate privind inițierea amestecurilor gazoase explozive prin surse potențiale de aprindere de natură diferită).

\section{References}

1. FDS User's Guide. Available at https://github.com/firemodels/fds/releases/download/FDS6.7.1/FDS User Guide.pdf

2. D. Florea, V. Pasculescu, N. Vlasin, M. Suvar, Virtual simulation of the initiation and expansion of a fire in a warehouse of goods, 3 (2017)

3. D. Florea, V. Pasculescu, N. Vlasin, M. Suvar, Virtual simulation of the initiation and expansion of a fire in a warehouse of goods, 4 (2017) 